\title{
Optimal Pricing and Capacity Under Well-Defined and Well-Known Deterministic Demand Fluctuations
}

\author{
Tchai Tavor ${ }^{1}$, Limor Dina Gonen ${ }^{2} \&$ Uriel Spiegel $^{3}$ \\ ${ }^{1}$ Department of Economics, The Max Stern Academic College of Emek Yezreel, Israel \\ ${ }^{2}$ Department of Economics and Business Administration, Ariel University, Israel \\ ${ }^{3}$ Department of Management, Bar-Ilan University, Israel, Visiting Professor, Department of Economics, University of \\ Pennsylvania, USA and Zefat College, Israel \\ Correspondence: Limor Gonen, Department of Economics and Business Administration, Ariel University, Israel.
}

Received: January 2, 2019 Accepted: March 19, 2019 Online Published: April 9, 2019

doi:10.5539/res.v11n2p15 URL: https://doi.org/10.5539/res.v11n2p15

\begin{abstract}
Fluctuations in demand require diverse considerations with respect to planned capacity. At peak periods, decreased capacity may result in supply shortages and thus in lower revenues and unachievable profits. In contrast, smaller capacity at off-peak periods reduces the substantial costs of large and unutilized capacity.

The questions to be addressed ask (i) what the optimal pricing policies are at peak and off-peak periods; (ii) what the optimal capacity is for profit maximization of the supplier; and furthermore (iii) how the shifting of demands from peak to off-peak periods may reduce fluctuation and impact profits.

The present paper develops a model that compares two cases. In Case 1 it is not possible to transfer partial demand from a peak period to an off-peak period, while in Case 2 it is possible to do so.

The comparison between the cases illustrates various results, some of which are less intuitive than others. For instance, a larger gap between the peak and off-peak periods leads to a larger optimal capacity in Case 1 than in Case 2. However, a smaller gap presents a different picture. When there is less willingness to switch demand between the periods, the capacity of Case 2 is larger than that of Case 1.
\end{abstract}

Keywords: peak and regular periods, optimal capacity, fluctuations, utilization

JEL Classification: L20, D21, D01

\section{Introduction}

The present paper begins with a question that asks what the common denominator is among the demands for an extensive variety of items in everyday life. For example, the planning of transportation services and public spaces considers the designated size and number of seats for a stadium, an airplane, a bus, or a shuttle; or the number of lanes on a highway connecting two large cities. In the area of construction, demands are considered in planning the number of hotel or motel rooms in specific recreation areas; or providing the number of seats or auditoriums for academic institutions. The electrical power industry needs to determine the capacity or size of electricity generators or turbines to be built for power stations. In the retail industry, the number of shelves and available products are due to the fluctuating demands of weekend and weekday shoppers, or of holiday season and regular day shoppers. With regard to health services, a hospital needs to provide the number of available beds to meet the deterministic fluctuating demands of winter (peak) and summer (off-peak) patients.

All of these examples have three unique characteristics, as further described below. First, the market repeatedly reveals cyclical fluctuations in demand at different times. Thus, a period of peak or high demand is followed by a different period of off-peak or regular demand, also referred to as low demand. Due to demand fluctuations, the first decision variable is the optimal capacity that is determined according to the size of the peak demand. (See Joskow and Tirole, 2007, p. 70, "Because electricity cannot be stored, the quantity of generating capacity must be at least as large as peak demand to avoid blackouts") See also Lamont (2013) for a discussion about storage capacity.

Second, the size of any item generates costs that are unaffected by the specific utilization of such size or capacity and that increase with increased capacity, regardless of its actual use. Capacity in itself generates cost. For example, the activating cost of an airplane depends positively, whether proportionally or not, upon its capacity or size. Boeing 767 has a lower 
cost per flight than Dreamliner.

Finally, additional kinds of costs depend positively on the specific use of the available capacity but are unaffected by unused capacity at an off-peak period. Following the above example regarding airplane activity, the longer the flight distance is, the greater is the cost (as is its benefit), regardless of the number of passengers traveling on the flight (e.g., more energy costs). This cost is not dependent upon the number of customers using the service or the product, but upon the sum of units of services or products that are used by the airplane. This cost can be included in the number of airplane flight miles that positively affects the use of fuel, the energy fee, and other fees for each flight regardless of the size of the airplane and the number of passengers on each flight. In addition, the larger that the number of passengers is on the airplane, the larger is the cost. A greater service cost is required for served food, etc.

The producer or supplier faces very different specific, deterministic, and well-defined demands at various times of a year, a week, or even a day. Sometimes deterministic demands are subject to seasonal variation or to variation during certain hours of a day, (e.g., traffic at rush hours as compared to traffic at regular hours). Another example is an airline. Peak period in the case of an airline is determined by peak demand during weekend flights from Thursday nights until Monday mornings, when most seats are occupied. The off-peak flights, in comparison, take place on the other days of the week. A different variation is in the demand for business flights during the early morning or late afternoon peak hours of demand, in contrast to the regular hours when flights have more empty seats due to low deterministic demand.

Fluctuations in demand result in various conflicting considerations regarding planned capacity. A reduction in capacity may lead to shortages in supplies and consequently to loss of revenues and unachievable profits at peak periods. On the other hand, smaller capacity at off-peak periods saves the significant costs that are due to unnecessarily large and unused capacity.

The questions for consideration are what the optimal pricing policies are at peak and off-peak periods; what the optimal capacity is that should lead to profit maximization of the supplier when all three characteristics mentioned above actually exist; and moreover, how the shifting demands from peak to off-peak periods may "narrow" fluctuation and affect profits.

This is the objective function of this paper. It develops a model based on peak load issues examined in the professional literature during the last several decades, as summarized below. The model analyzes and develops comparisons between cases with and without transition of demands between peak and regular periods.

The early literature of peak load pricing goes back to the work of Bye $(1926,1929)$, who first developed the peak load model (Ault and Ekelund (1987)), Lewis (1941) Houthakker (1951), Steiner (1957), and Boiteux (1949) were the originators of the basic theory of peak load pricing, and the subsequent literature was based upon their works. The literature of the late 1960's and 1970's incorporated demand uncertainties and the consequent supply shortfalls and rationing. The work of Brown and Johnson (1969) kindled a broader theoretical interest in the treatment of stochastic demand and its consequences for expected welfare. Subsequent contributions by Visscher (1973), Crew and Kleindorfer (1976; 1978), Carlton (1977), and Sherman and Visscher (1978) extended the theory to account explicitly for the costs of rationing resulting from alternative forms of rationing. Crew and Kleindorfer (1976) also expanded the stochastic model to a setting with multiple technologies and periods. Chao (1983) and Kleindorfer and Fernando (1993) later extended the literature to account for supply-side uncertainties. All of these papers assume that production costs of outage can be measured, and that rationing can be implemented based on these measurements. Telson (1975) and Munasinghe and Sanghvi (1988) provided a framework to measure outage costs, and several utilities have incorporated these measurements into rate setting and investment planning. For a detailed literature review see Crew, Fernando and Kleindorfer (1995). Other authors who contributed to the theory of peak load pricing are Laffont and Tirole (2000), Shy (2001), and Calzada (2003).

The literature of deterministic demand fluctuations exists especially in the area of electricity, in which the size or capacity of a plant is planned with the possibility of pumped storage of energy and other devices of storable forms. See Horsley and Worbel (2002) and Steffen and Weber (2013) regarding pumped-hydro storage plants that can provide required flexibility of supplies and derive optimal and efficient storage capacity. The environment in the current paper does not allow these degrees of flexibility in the supply, and the capacity should be derived under very rigid circumstances.

Analytical, practical, and daily examples of deterministic fluctuating demands described in the recent literature are summarized below. Some of them can be modified by our new model.

Investigation of optimal bus size is one example. During peak hours such as rush hour, the demand for service is high in comparison to the low demand during regular hours. More buses of smaller capacity, combined with more frequent service can be one possible response to the high demand, but it requires a greater cost per seat (Yang, et al., 2015). Ibeas et al., (2014) propose an optimization model for designing the sizes of buses traveling on public transport networks by minimizing system operating costs and user costs. The proposed model takes into account congestion in the public 
transport system and considers elastic demand. This allows for analyzing how modifications made to the operational characteristics of the public transport system may affect changes in the mode of transport used by passengers.

Jiang et al., (2014) propose an optimization model for determining headways of suburban bus routes. Their model reduces operating costs and user costs. Included among the latter are waiting time cost as well as crowding cost. In contrast to the present paper, however, the above referenced model ignores all additional cost due to the size of a bus.

Another practical example is airplane size in terms of cargo capacity or passenger seats. It considers the optimal number of available airplane seats in the given peak and regular seasons. More availability might lead to more expenses due to the size of the airplane and to unused empty seats in regular seasons. Kopsch (2012) discusses these ideas and shows that aggregate demand for domestic air travel in Sweden is elastic in the short run. Positive cross-price elasticity is found between rail and air travel.

An additional matter included in this category is class size in schools. Several economists such as Lazear (2001) discuss the advantages of larger classes along with their disadvantages of cost.

Fluctuations in demand also relate to the tourism sector in which governments and businesses need high-quality tourism demand analysis to develop efficient public policy and make good business decisions. Considerable efforts have been made to analyze tourism demand and develop explanatory models, which assist in making informed critical decisions. Peng et al. (2015) generalize the demand elasticities at a disaggregated level to enhance the understanding of tourist behavior and diverse tastes.

The paper also contributes to more effective international tourism forecasts; and development and investment strategies including public policy, marketing programs, and efforts to maintain and enhance destination competitiveness. Tourism also faces fluctuations of demands in air transportation in different regions. Zervas et al. (2017) explore the economic impact of the sharing economy on incumbent firms by studying the case of Airbnb, a prominent platform for short-term accommodations. They analyze Airbnb's entry into the state of Texas and quantify its impact on the Texas hotel industry over the subsequent decade.

Another aspect of tourism mentioned both by Peng et al. (2015) and Zervas et al. (2017) concerns the size of a hotel, which is determined according to the number of rooms for which peak and low demands fluctuate. Cross (1997) also suggests that an important factor related to a hotel or motel facility is size in terms of the quantity of rooms. Demand forecasting allows for allocating perishable assets across rate classes, deciding when and to what extent to overbook, and determining the price to charge for different rate classes. See in addition Lieberman (1992); Smith et al., (1992); Geraghty and Johnson (1997). All of the abovementioned authors focus on revenue maximization due to the cost structure and economics of perishable assets. For example, the fixed cost of running a hotel is high so that once the hotel occupancy rate is above the break-even occupancy rate, the contribution to profit and overhead per each additional customer is high.

An additional example relates to the supply of electricity. The electricity supply involves fluctuations in demand according to the hours of the day, and thus a discussion regarding capacity is necessary, as presented in the papers further described below.

Additional discussion regarding the optimal size of electric power stations, assuming demand fluctuations and transformation of demand, leads to more balanced demand and reduction of turbine size, thus lessening the cost of capacity. This issue of transformation of demand is also used in the model below. For example, Ashok (2006) presents a load model for minimizing the total electricity cost while satisfying production, process flow, and storage constraints (i.e. capacity) by controlling it through various tariff structures. The case study of a steel plant shows that significant reductions in peak-period demand and electricity cost are possible with optimal load schedules. The utility can also obtain significant reduction in the peak coincident demand if large industries optimally reschedule their productions in response to a time-of-use (TOU) tariff. We apply this approach by shifting demand from peak to regular period.

In contrast to Collard-Wexler (2013) who investigates the role of demand shocks in the ready-mix concrete plants industry that faces considerable uncertainty regarding future demand for its products, the present paper deals with periodic and known deterministic demands.

The primary innovation of the present paper is that it introduces two elements of costs from the size or capacity of an aircraft, a hotel, bus, or facility for the production of electricity. These capacity-related costs are in addition to other current production costs of units actually supplied. We also examine the possibility of transferring demand from peak periods to low periods in order to save costs of "size" and efficiently regulate the supply of deterministic fluctuating demand for the sake of increased profits. 


\section{The Theoretical Model}

\subsection{Case 1}

The present analysis begins with Case 1 in which two separated and segmented demand curves for airplane flights exist. One demand, $D^{H}$, is the peak period high demand, $\mathrm{H}$, while the other demand, $D^{L}$, is the off-peak period low demand, $\mathrm{L}$.

Although the general model can be applied to at least each of the six cases presented in Table 1, below, the present paper applies it to the first case of airplane flights.

Table 1. Examples of fluctuated demand between peak and off peak period

\begin{tabular}{|c|c|c|c|}
\hline The Case & Capacity & Peak Period & Off-Peak Period \\
\hline $\begin{array}{l}\text { Aircraft } \\
\text { Train cars } \\
\text { Public transportation } \\
\text { Bus }\end{array}$ & $\begin{array}{l}\text { Size in terms of seats } \\
\text { or cargo space }\end{array}$ & $\begin{array}{l}\text { Weekend flights } \\
\text { Holiday period flights }\end{array}$ & $\begin{array}{l}\text { Daily flights during } \\
\text { weekdays }\end{array}$ \\
\hline Highway & $\begin{array}{l}\text { Number of lanes on } \\
\text { the highway }\end{array}$ & Rush hours of the day & $\begin{array}{l}\text { Regular hours of the } \\
\text { day }\end{array}$ \\
\hline Electricity supply & Size of the turbine & $\begin{array}{l}\text { Daytime/winter season } \\
\text { electricity use }\end{array}$ & $\begin{array}{l}\text { Nighttime/summer } \\
\text { season electricity use }\end{array}$ \\
\hline Department stores & $\begin{array}{l}\text { Size of stores or } \\
\text { shelves }\end{array}$ & $\begin{array}{l}\text { Weekend days or } \\
\text { holiday periods }\end{array}$ & $\begin{array}{l}\text { Weekdays } \\
\text { off-season periods }\end{array}$ \\
\hline Hospitalization service & $\begin{array}{l}\text { Number of available } \\
\text { rooms or beds }\end{array}$ & $\begin{array}{l}\text { Winter days or seasons } \\
\text { with seasonal illnesses }\end{array}$ & $\begin{array}{l}\text { Summer days with } \\
\text { fewer illnesses }\end{array}$ \\
\hline $\begin{array}{l}\text { Recreation and hotel } \\
\text { services }\end{array}$ & $\begin{array}{l}\text { Number of rooms for } \\
\text { tourists }\end{array}$ & $\begin{array}{l}\text { Vacation season } \\
\text { Hawaii in summer } \\
\text { Colorado in winter }\end{array}$ & Regular seasons \\
\hline
\end{tabular}

The equations for the fluctuating deterministic demands are as follows:

(1) $D^{H}: \quad P_{1}^{H}=H \cdot d i s^{\alpha}-Q_{H}$ or $\left(1^{\prime}\right) Q_{H}=H \cdot d i s^{\alpha}-P_{1}^{H}$

(2) $D^{L}: \quad P_{1}^{L}=L \cdot d i s^{\alpha}-Q_{L}$ or $\quad\left(2^{\prime}\right) Q_{L}=L \cdot d i s^{\alpha}-P_{1}^{L}$

Where $H>L$, the price elasticity at a peak period is relatively low in comparison to the price elasticity at a low period. dis represents the flight distance of the airplane.

The firm faces deterministic demands, and its operation cost for the flight service function can be broken down into three components of capacity costs and variable costs.

Capacity costs such as depreciation and devaluation over time are proportional to the size of the airplane or the cost of maintaining machinery and equipment that are more valuable for a large capacity. The notation of capacity is $K$ and $b$ is the cost per unit of the airplane capacity that is measured, for example, by the number of seats in the airplane. Thus $b \cdot K=$ total capacity cost that is proportional to the size or capacity itself.

Variable costs that depend on the flight distance and are possibly incurred following a certain number of flights are $a \cdot d i s$, where $a$ represents the cost per unit of flight distance regardless of the number of passengers. Other variable costs are proportional to the number of passengers occupying the airplanes seats. $\mathrm{C}$ reflects the cost per passenger per flight distance unit.

Thus, $\mathrm{C} \cdot \sum_{i=1}^{2} Q_{i}$ represents the third item included in the cost function. Therefore, the total costs function of the airline using an airplane of size $K$ is:

(3) $T C=a \cdot d i s+C\left(Q_{H}+Q_{L}\right) \cdot d i s+b \cdot K$

where coefficient $a$ represents the marginal cost of the use of the aircraft due to another unit of distance dis.

where $b$ represents the marginal cost of increasing the capacity of the aircraft by an additional unit of size.

where $C$ represents the marginal operational cost of providing service to another passenger in the aircraft.

The profit function in model $1, \pi_{1}$, is as follows:

(4) $\operatorname{Max} \pi_{1}=P_{1}^{H} Q_{H}+P_{1}^{L} Q_{L}-a \cdot \operatorname{dis}-C\left(Q_{H}+Q_{L}\right) \cdot \operatorname{dis}-b \cdot K=P_{1}^{H} K+P_{1}^{L} Q_{L}-a \cdot \operatorname{dis}-C\left(K+Q_{L}\right) \cdot \operatorname{dis}-$

$b \cdot K$ 
Due to the deterministic demand there is no reason that capacity level, $K$, will be larger than the actual supply of seats at a peak period.

By assigning equations (1') and (2') in equation, (3) we obtain:

(4') $\max _{P_{1}^{H}, P_{1}^{L}} \pi_{1}=P_{1}^{H}\left(H \cdot d i s^{\alpha}-P_{1}^{H}\right)+P_{1}^{L}\left(L \cdot d i s^{\alpha}-P_{1}^{L}\right)-a \cdot d i s-C\left(H \cdot d i s^{\alpha}-P_{1}^{H}+L \cdot d i s^{\alpha}-P_{1}^{L}\right) \cdot d i s-b \cdot$ $K$

$\alpha$ is a positive coefficient indicating the willingness to pay a higher price in dollars for a given quantity (flight) due to a longer flight distance.

For $\alpha=1$ the price increases linearly with distance.

For $\alpha \neq 1$ the price increases with distance, but not necessarily linearly.

The First Order Conditions (F.O.C.) that are derived with respect to the decision variables $P_{1}^{H}$ and $P_{1}^{L}$ are as follows:

(5) $\frac{\partial \pi_{1}}{\partial P_{1}^{H}}=H \cdot d i s^{\alpha}-2 P_{1}^{H}+C \cdot d i s+b=0 \quad \Rightarrow \quad P_{1}^{H}=\frac{H \cdot d i s^{\alpha}+C d i s+b}{2}$

(6) $\frac{\partial \pi_{1}^{1}}{\partial P_{1}^{L}}=L \cdot d i s^{\alpha}-2 P_{1}^{L}+C \cdot d i s=0$

From equations (5) and (6) we obtain the equilibrium prices in Case 1, the case in which it is not possible to transfer passengers from a peak flight period to an off-peak period as follows:

(7) $P_{1}^{H}=\frac{H \cdot d i s^{\alpha}+C \cdot d i s+b}{2}$

and

(8) $P_{1}^{L}=\frac{L \cdot d i s^{\alpha}+C \cdot d i s}{2}$

And optimal equilibrium quantities are derived from (7), (8) and (1) and (2):

(9) $Q_{1}^{H}=K=\frac{H \cdot d i s^{\alpha}-C \cdot d i s-b}{2}$

(10) $Q_{1}^{L}=\frac{L \cdot d i s^{\alpha}-C \cdot d i s-b}{2}$

Where $\mathrm{K}$ represents the capacity of seats.

From (9) and (10) we get the number of seats that remain unoccupied during the low period:

(11) $\left(Q_{1}^{H}-Q_{1}^{L}\right)=\frac{(H-L) \cdot d i s^{\alpha}}{2}$

\subsection{Case 2}

Case 2 uses the idea of transferring demand from peak period to off-peak period. In some sense we adopt a similar idea of transferring surplus from an off-peak to a peak period in the electricity market. See Crampes and Moreaux (2010).

Case 2 allows for transferring passengers from a peak period or high season, $\mathrm{H}$, to an off-peak period or low season, $\mathrm{L}$, in order to minimize the number of unoccupied seats. The process that is also referred to as the option for Moving Passengers (MP), provides an imperfect substitute product with which some consumers prefer to transfer their flights from the peak to the low periods. Moving Passengers are those passengers who postpone their flights from $\mathrm{H}$ to $\mathrm{L}$. This possibility of Moving Passengers should change the demand structure. We assume that the demand decreases during the peak period since the new scenario provides for MP. Without MP, the demand during the peak period remains as presented in equation (1) or (1'). Several kinds of demand functions at a peak period that are due to Moving Passengers are considered with different kinds of linear and non-linear functions. The set of equations presented below provides most interesting results regarding capacity, pricing and profits. We also considered other demands that can be transferred upon request.

The following presents the interrelationship between the demand of passengers who consume the airline service (flights) during a high or peak period; and the demand of Moving Passengers who postpone their flights to a low or off-peak period.

(12) $D^{H}: Q^{H}=H \cdot d i s^{\alpha}+\varepsilon P^{M P}-P^{H}$

(13) $\varepsilon>0$ represents the sensitivity of the peak quantity demanded towards the price of a substitute good that is a postponed flight at a low (off-peak) season. $D^{L}: Q^{L}=L \cdot d i s^{\alpha}-P^{L}$

(14) $D^{M P}: Q^{M P}=M P \cdot d i s^{\alpha}+\gamma \cdot\left(P^{H}-P^{M P}\right)-P^{M P}$

Coefficient $\gamma>0$ represents the change in the quantity demanded in units of flights postponed from peak to off-peak periods due to the discount in price given at an off-peak period. This kind of change is more realistic.

It is assumed that, $D^{H}$, the actual demand at a peak period is affected negatively by the price at peak periods, $P^{H}$, and as expected also positively by $P^{M P}$ due to the fact the $Q^{H}$ and $Q^{M P}$ are both substitute goods, but not necessarily 
complete substitutes.

The demand at an off-peak period is affected linearly and negatively only by its own price.

Our most important innovation is with regard to $D^{M P}$. It is added to the market where the quantity demanded for postponed flights, $Q^{M P}$, is affected negatively by $P^{M P}$ as expected, but at the same time positively by the price gap or discount in price of $\left(P^{H}-P^{M P}\right)$. Due to a larger discount between the prices, we expect that more passengers postpone their flights to off-peak periods, enabling much more revenue at an off-peak period. We believe that the main motivation of passengers to postpone their flights from a peak period to an off-peak period can be achieved with a larger discount in price that may compensate for the delay in their flights. $\gamma$ represents the sensitivity of the postponed demand to the discount in price. This kind of interrelationship between markets is more realistic. Using the appropriate simulations below, we can find how this kind of transfer of passengers should affect the capacity and the different pricing of $P^{H}, P^{L}$ and $P^{M P}$. Comparisons are made between Case 1 and Case 2 with regard to several decision variables.

The new profit function in Case 2 that includes the possibility of Moving Passengers, $\pi_{2}$, is:

(15) $\pi_{2}=P^{H} \cdot Q^{H}+P^{L} \cdot Q^{L}+P^{M P} \cdot Q^{M P}-T C$

or

(16) $\pi_{2}=\left(H \cdot d i s^{\alpha}+\varepsilon \cdot P^{M P}-P^{H}\right) \cdot P^{H}+\left(L \cdot d i s^{\alpha}-P^{L}\right) \cdot P^{L}+\left[M P \cdot d i s^{\alpha}+\gamma \cdot\left(P^{H}-P^{M P}\right)-P^{M P}\right] \cdot P^{M P}-C \cdot$

$\operatorname{dis}\left[H \cdot d i s^{\alpha}+\varepsilon \cdot P^{M P}-P^{H}+L \cdot d i s^{\alpha}-P^{L}+M P \cdot d i s^{\alpha}+\gamma \cdot\left(P^{H}-P^{M P}\right)-P^{M P}\right]-b \cdot\left(H \cdot d i s^{\alpha}+\varepsilon \cdot P^{M P}-\right.$ $\left.P^{H}\right)-a \cdot d i s$

Where $\varepsilon>0$ represents the substitute effect of $P^{M P}$ on $Q^{H}$ and $\gamma>0$ represents the idea that the demand of Moving Passengers is affected positively by a larger discount in the ticket price that is the gap between $P^{H}$ and $P^{M P}$.

The F.O.C. with respect to three decision variables, $P^{H}, P^{L}, P^{M P}$ are:

(17) $\frac{\partial \pi_{2}}{\partial P^{H}}=H \cdot d i s^{\alpha}-\varepsilon \cdot P^{M P}-2 P^{H}-\gamma \cdot P^{M P}+c \cdot d i s \cdot(1-\gamma)+b=0 \Rightarrow P^{H}=\frac{H \cdot d i s^{\alpha}+C \cdot d i s \cdot(1-\gamma)+b+(\varepsilon+\gamma) \cdot P^{M P}}{2}$.

(18) $\frac{\partial \pi_{2}}{\partial P^{L}}=L \cdot d i s^{\alpha}-2 P^{L}+C \cdot d i s=0 \Longrightarrow P^{L}=\frac{L \cdot d i s^{\alpha}+C \cdot d i s}{2}$

and

(19) $\frac{\partial \pi_{2}}{\partial P^{M P}}=\varepsilon \cdot P^{H}+M P \cdot d i s^{\alpha}+\gamma \cdot P^{H}-2(1+\gamma) \cdot P^{M P}-\varepsilon \cdot C \cdot d i s+(1+\gamma) C \cdot d i s-\varepsilon \cdot b=0 \Longrightarrow P^{H}=$

$\frac{-M P \cdot \text { dis }^{\alpha}-C \cdot d i s \cdot(1+\gamma-\varepsilon)+\varepsilon \cdot b+2 \cdot(1+\gamma) \cdot P^{M P}}{\varepsilon+\gamma}$

By equations (17) and (19) we get:

(20) $(\varepsilon+\gamma) H \cdot$ dis $^{\alpha}+(\varepsilon+\gamma) \cdot C \cdot d i s \cdot(1-\gamma)+b \cdot(\varepsilon+\gamma)+(\varepsilon+\gamma)^{2} \cdot P^{M P}=-2 M P \cdot$ dis $^{\alpha}-2 C \cdot d i s$.

$(1+\gamma-\varepsilon)+2 \varepsilon \cdot b+4 \cdot(1+\gamma) \cdot P^{M P}$

Therefore,

(21) $P^{M P}=\frac{[(\varepsilon+\gamma) \cdot H+2 M P] \cdot d i s^{\alpha}+[(\varepsilon+\gamma) \cdot(1-\gamma)+2(1+\gamma-\varepsilon)] \cdot C d i s+b \cdot(\varepsilon+\gamma)}{4 \cdot(1+\gamma)-(\varepsilon+\gamma)^{2}}$

And from (17) we get:

$$
P^{H}=\frac{4(1+\gamma) \cdot H \cdot d i s^{\alpha}+2(\varepsilon+\gamma) \cdot M P \cdot d i s^{\alpha}+\left[4(1-\gamma)^{2}+2(\varepsilon+\gamma) \cdot(1+\gamma-\varepsilon)\right] \cdot c \cdot d i s}{2\left[4(1+\gamma)-(\varepsilon+\gamma)^{2}\right]}+\frac{\left[4(1+\gamma)-(\varepsilon+\gamma)^{2}+(\gamma-\varepsilon) \cdot(\varepsilon+\gamma)\right] \cdot b}{2\left[4(1+\gamma)-(\varepsilon+\gamma)^{2}\right]}
$$

These values cannot be solved analytically and cannot be compared to the results in Case 1, above.

The tables below that are based on specific values of the parameters, introduce results regarding quantities, pricing policy, profits, and the difference in profits between Case 1 and Case 2.

\section{Comparative Static Analysis}

In the previous sections we develop the model of profit maximization policies in a market with a perpetual cycle of fluctuating demands. The model includes two main factors. The first one is the gap in the demands between periods, which is measured by the value $(\mathrm{H}-\mathrm{L})$. A larger gap $(\mathrm{H}-\mathrm{L})$ indicates larger fluctuations in the demands between periods. The second factor is the value of the coefficient $\gamma$. It represents the sensitivity of the quantity of Moving Passengers, $\mathrm{Q}^{\mathrm{MP}}$, towards a discounted flight ticket in exchange for postponing a flight from a peak period with high 
demand to an off-peak period with low (regular) demand.

Since equilibrium values of prices, quantities, etc. in the model of the two cases cannot be determined and compared analytically, this section examines them with many simulations using several parameters, thus allowing us to define some interesting observations. The first stage of the investigation considers the effects of changes in values of $\mathrm{H}$ for given values of $\mathrm{L}$ and $\gamma$ on the values of prices, quantities, profits, optimal capacities, and empty seats (ES). The ES are the difference between the capacity of seats determined by ticket sales at peak periods, and the actual number of seats used during an off-peak period. Finally, the study examines how changes in $\mathrm{H}$ also affect the utilization index factor, UI. This factor is measured in different ways in Case 1 and in Case 2. It represents the ratio between ES and the capacity $\mathrm{K}_{\mathrm{i}}$.

In Case 1, in which there are no Moving Passengers, the value of $\mathrm{UI}_{1}$ is as follows:

$$
\mathrm{UI}_{1}=1-\frac{E S_{1}}{K_{1}}
$$

In Case 2 that allows for the possibility of Moving Passengers, the value of $\mathrm{UI}_{2}$ is as follows:

$$
\mathrm{UI}_{2}=1-\frac{E S_{2}}{K_{2}}
$$

As can be expected, the utilization in Case 2 is higher than in Case 1. However, the question is whether this is due to a reduction in $\mathrm{ES}_{2}$ in comparison to $\mathrm{ES}_{1}$; or perhaps also due to changes in capacity $\mathrm{K}_{2}$ in comparison to capacity $\mathrm{K}_{1}$ in Case 1. These possibilities are discussed below in the comparisons between cases.

For a given value of $\mathrm{L}$ the immediate conclusion is that as the value of $\mathrm{H}$ increases, the capacity, $\mathrm{K}$, is larger for either case. As a result, the value of ES (empty seats) at a regular (off- peak) period is larger. Due to the changes in K and ES, the UI (utilization index) is diminishing, especially in Case 2.

The second issue considers the effects of parameter $\gamma$ that is defined above, on the same variables.

The value of capacity, $\mathrm{K}$ is diminishing in Case 2 due to an increase in $\gamma$ that represents a greater readiness of Moving Passengers to transfer from a peak to an off-peak period. This substituity effect allows the firm to reduce the capacity, especially when it is relatively small. In any case, for any $\gamma>0$ the capacity in Case 1 is larger than in Case 2.

The effect of $\gamma$ on ES is negative in Case 2 (while it is of no effect in Case 1). As a result, we can conclude that UI is higher in Case 2 in which $\gamma$ is higher.

The last and the most important comparisons relate to the effects of parameters $\mathrm{H}, \mathrm{L}$, and $\gamma \quad$ on the gap in the values of most of the above variables between Cases 1 and 2.

It is clear that opening the markets to transferring demands (with Moving Passengers) from a peak to an off-peak period allows for a larger profit in Case 2 in comparison to Case 1 . This is especially so when the gap is larger between $\mathrm{H}$ and $\mathrm{L}$, with either a larger $\mathrm{H}$ than a given $\mathrm{L}$ or vice versa, a lower $\mathrm{L}$ than a given $\mathrm{H}$. The same is true regarding $\gamma$. A larger value of $\gamma$ that represents a greater readiness to shift flights from peak to off-peak periods, enables the airline to gain more profits. Yet the question is whether this is achieved by increasing or decreasing capacity, empty seats, or utilization of capacity; or by charging lower or higher prices and selling more or less tickets in the transition from the situation of Case 1 into Case 2.

All of these considerations are discussed and illustrated in the graphs below.

Table 2 and Figures 1and 2 describe the influences of $\mathrm{H}$ changes on several values.

Table 2 describes the effect of changes of $\mathrm{H}$ on quantities of empty seats and profits.

The table shows that an increase in $\mathrm{H}$ increases both the quantity of empty seats and profits. However, the effect of $\mathrm{H}$ on both variables is more significant and larger in Case 2 than in Case 1. 
Table 2. The results of changing the value of $\mathrm{H}$

$\begin{array}{cccccccc}\mathrm{L} & \text { dis } & a & \mathrm{a} & \mathrm{b} & \mathrm{C} & \gamma & \xi \\ 80 & 1 & 1 & 10 & 20 & 40 & 0.4 & 0.3\end{array}$

Comparison of Cases 1 and 2 for the following values of the parameters:

\begin{tabular}{c|c|c|c|c|c|c|c|c|c}
\hline $\mathbf{H}$ & $\mathbf{Q H 1}(\mathbf{K})$ & $\mathbf{Q H 2}(\mathbf{K})$ & $\mathbf{E S 1}$ & $\mathbf{E S 2}$ & $\boldsymbol{\Sigma Q 1}$ & $\boldsymbol{\Sigma Q 2}$ & $\boldsymbol{\pi 1}$ & $\boldsymbol{\pi} 2$ & $\Delta \boldsymbol{\pi}$ \\
\hline 300 & 120 & 122.16 & 100 & 40.52 & 140 & 203.80 & 14790 & 23799.16 & 9009.16 \\
\hline 295 & 117.5 & 119.69 & 97.5 & 38.19 & 137.5 & 201.20 & 14196.25 & 23041.62 & 8845.37 \\
\hline 290 & 115 & 117.23 & 95 & 35.86 & 135 & 198.60 & 13615 & 22297.79 & 8682.79 \\
\hline 285 & 112.5 & 114.76 & 92.5 & 33.53 & 132.5 & 196.00 & 13046.25 & 21567.65 & 8521.40 \\
\hline 280 & 110 & 112.30 & 90 & 31.20 & 130 & 193.39 & 12490 & 20851.21 & 8361.21 \\
\hline 275 & 107.5 & 109.83 & 87.5 & 28.87 & 127.5 & 190.79 & 11946.25 & 20148.47 & 8202.22 \\
\hline 270 & 105 & 107.37 & 85 & 26.54 & 125 & 188.19 & 11415 & 19459.43 & 8044.43 \\
\hline 265 & 102.5 & 104.90 & 82.5 & 24.22 & 122.5 & 185.59 & 10896.25 & 18784.09 & 7887.84 \\
\hline 260 & 100 & 102.43 & 80 & 21.89 & 120 & 182.98 & 10390 & 18122.45 & 7732.45 \\
\hline 255 & 97.5 & 99.97 & 77.5 & 19.56 & 117.5 & 180.38 & 9896.25 & 17474.50 & 7578.25 \\
\hline 250 & 95 & 97.50 & 75 & 17.23 & 115 & 177.78 & 9415 & 16840.25 & 7425.25 \\
\hline 245 & 92.5 & 95.04 & 72.5 & 14.90 & 112.5 & 175.17 & 8946.25 & 16219.71 & 7273.46 \\
\hline 240 & 90 & 92.57 & 70 & 12.57 & 110 & 172.57 & 8490 & 15612.86 & 7122.86 \\
\hline
\end{tabular}

$\mathrm{QH}_{\mathrm{i}}$ - The number of passengers during the peak period in case $\mathrm{i}$, while $\mathrm{i}=1,2$.

$\mathrm{ES}_{\mathrm{i}}-$ The number of empty seats in the peak season in case $\mathrm{i}$, while $\mathrm{i}=1,2$.

$\Sigma \mathrm{Q}_{\mathrm{i}}$ - The total number of passengers in case $\mathrm{i}$, while $\mathrm{i}=1,2$.

$\Pi i$ - The profit in case $i$, while $i=1,2$.

$\Delta \pi-$ The difference in profit between case 2 and case 1

Figure 1 describes the effect of the change in $\mathrm{H}$ on occupied seats. The figure shows that $\mathrm{H}$ positively affects the peak period quantities, again more significantly in Case 2; but it has no effect at a regular period. The inverse effect of changes in $\mathrm{H}$ are on the $\mathrm{UH}$ index. $\mathrm{UH}$ decreases by increasing $\mathrm{H}$, especially and more significantly in Case 2.

The following results discuss the effect of the $\gamma$ variable, which positively affects unoccupied seats as well as profit in Case 2, but has no effect in Case 1.

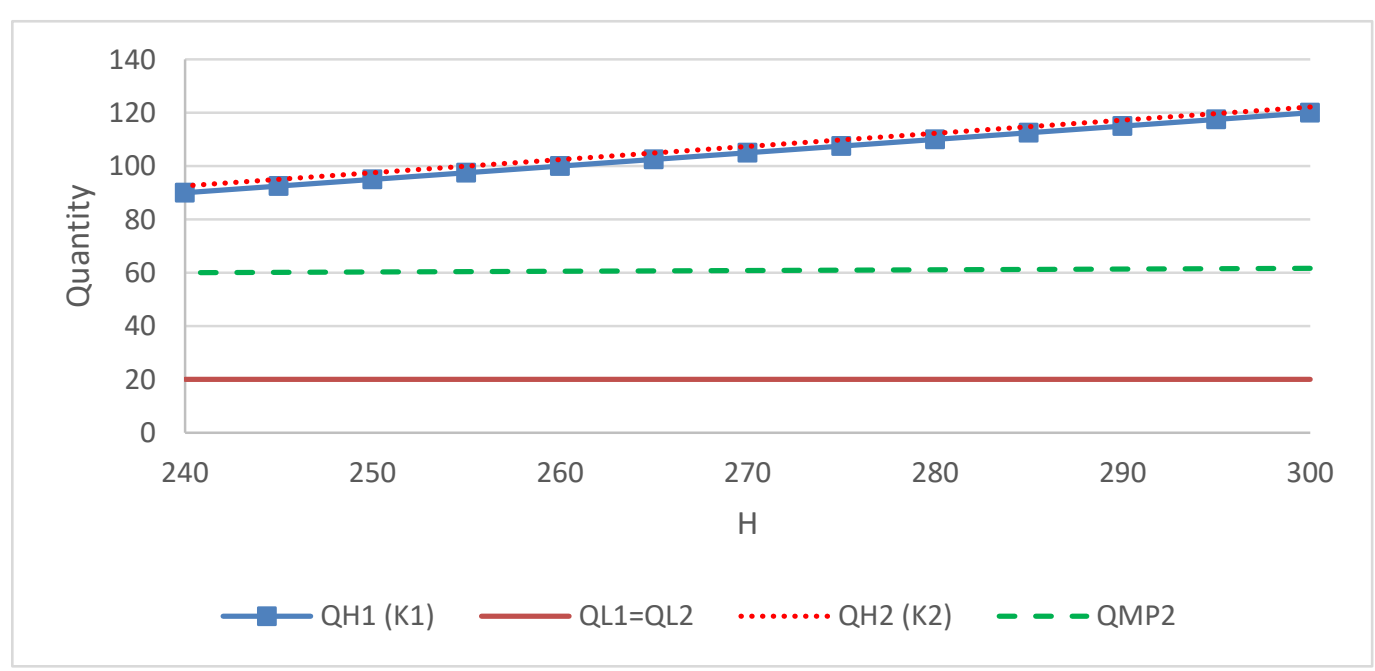

Figure 1. The effect of the change in $\mathrm{H}$ on occupied seats

Figure 2 illustrates the effect of the $\mathrm{H}$ change on the UH index. From the chart it can be seen that the index in Model 2 is higher than the index in Model 1. When an increase in $\mathrm{H}$ decreases the index in both models, in model 2 the effect is stronger. 


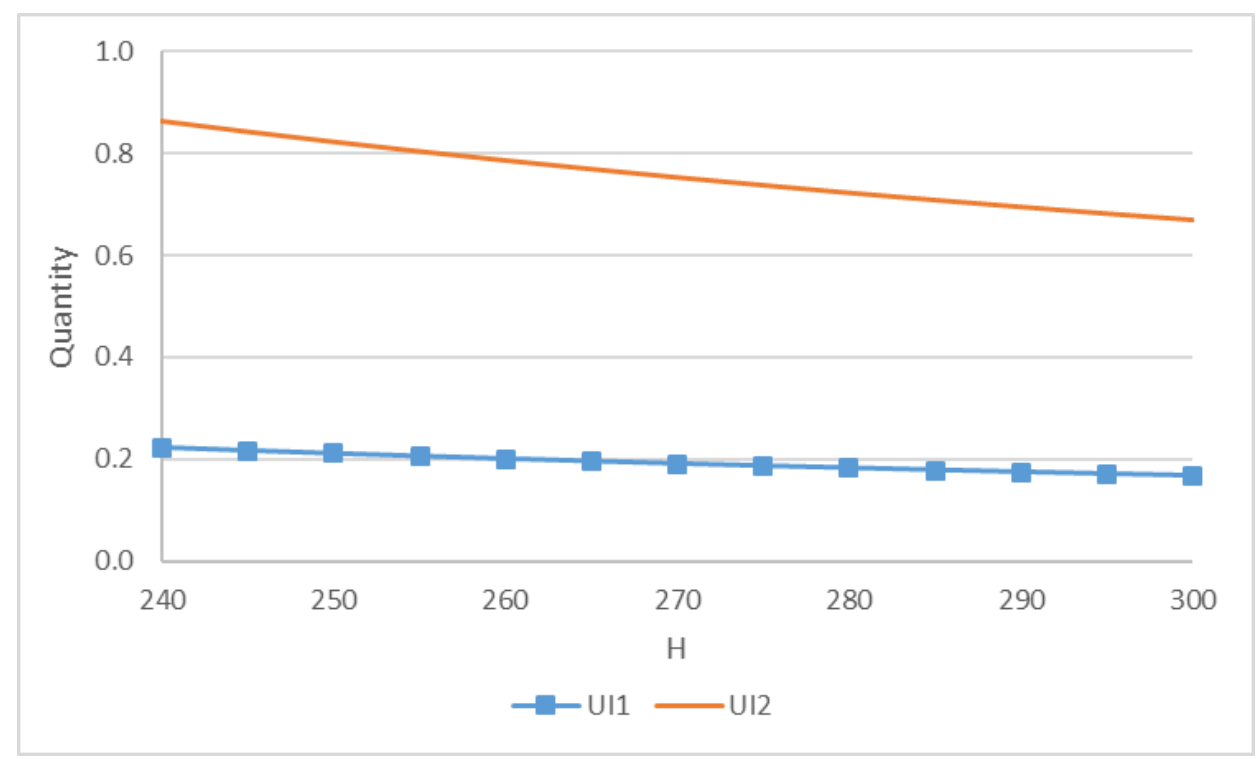

Figure 2. The effect of the $\mathrm{H}$ change on the UH index

Table 3 and Figures 3 and 4 describe the influences of $\gamma$ changes on several values.

A comparative analysis is done with respect to changing the values of $\gamma$ for the following given values of $\mathrm{H}$.

Table 2 describes the effect of $\gamma$ on the quantities of empty seats and profits. The table shows that an increase in $\gamma$ increases the overall quantity and profit in Case 2 but does not change the overall quantity and profit in Case 1 . Therefore, the change in profit increases when comparing the two cases.

Table 3. The results of changing the value of $\gamma$

Comparison of Cases 1 and 2 for the following values of the parameters:

\begin{tabular}{|c|c|c|c|c|c|c|c|c|c|}
\hline $\mathrm{H}$ & $\mathrm{L}$ & di & & $\mathrm{a}$ & & $\mathrm{b}$ & C & $\xi$ & \\
\hline 300 & 80 & 1 & & & & 20 & 40 & & \\
\hline$\gamma$ & QH1 (K) & QH2 (K) & ES1 & ES2 & $\Sigma Q 1$ & $\Sigma \mathbf{Q} 2$ & $\pi 1$ & $\pi 2$ & $\Delta \pi$ \\
\hline 0.5 & 120 & 118.13 & 100 & 27.39 & 140 & 208.88 & 14790 & 24556.42 & 9766.42 \\
\hline 0.49 & 120 & 118.55 & 100 & 28.73 & 140 & 208.36 & 14790 & 24478.90 & 9688.90 \\
\hline 0.48 & 120 & 118.96 & 100 & 30.07 & 140 & 207.84 & 14790 & 24401.80 & 9611.80 \\
\hline 0.47 & 120 & 119.36 & 100 & 31.40 & 140 & 207.33 & 14790 & 24325.09 & 9535.09 \\
\hline 0.46 & 120 & 119.77 & 100 & 32.72 & 140 & 206.82 & 14790 & 24248.78 & 9458.78 \\
\hline 0.45 & 120 & 120.17 & 100 & 34.04 & 140 & 206.31 & 14790 & 24172.87 & 9382.87 \\
\hline 0.44 & 120 & 120.57 & 100 & 35.35 & 140 & 205.80 & 14790 & 24097.36 & 9307.36 \\
\hline 0.43 & 120 & 120.97 & 100 & 36.65 & 140 & 205.30 & 14790 & 24022.23 & 9232.23 \\
\hline 0.42 & 120 & 121.37 & 100 & 37.94 & 140 & 204.80 & 14790 & 23947.49 & 9157.49 \\
\hline 0.41 & 120 & 121.77 & 100 & 39.23 & 140 & 204.30 & 14790 & 23873.13 & 9083.13 \\
\hline 0.4 & 120 & 122.16 & 100 & 40.52 & 140 & 203.80 & 14790 & 23799.16 & 9009.16 \\
\hline 0.39 & 120 & 122.55 & 100 & 41.79 & 140 & 203.31 & 14790 & 23725.56 & 8935.56 \\
\hline 0.38 & 120 & 122.94 & 100 & 43.06 & 140 & 202.82 & 14790 & 23652.34 & 8862.34 \\
\hline
\end{tabular}

$\mathrm{QH}_{\mathrm{i}}-$ The number of passengers during the peak period in case $\mathrm{i}$, while $\mathrm{i}=1,2$.

$E S_{i}-$ the number of empty seats in a peak season in case $i$, while $i=1,2$.

$\Sigma \mathrm{Q}_{\mathrm{i}}$ - The total number of passengers in case $\mathrm{i}$, while $\mathrm{i}=1,2$. 
$\Pi i$ - The profit in case $i$, while $i=1,2$.

$\Delta \pi-$ The difference in profit between case 2 and case 1

Figure 3 illustrates that the effect of the change in $\gamma$ on the quantities during the peak period has no effect on the regular period; but with an increase of the value $\gamma$, actual quantities at peak period decrease.

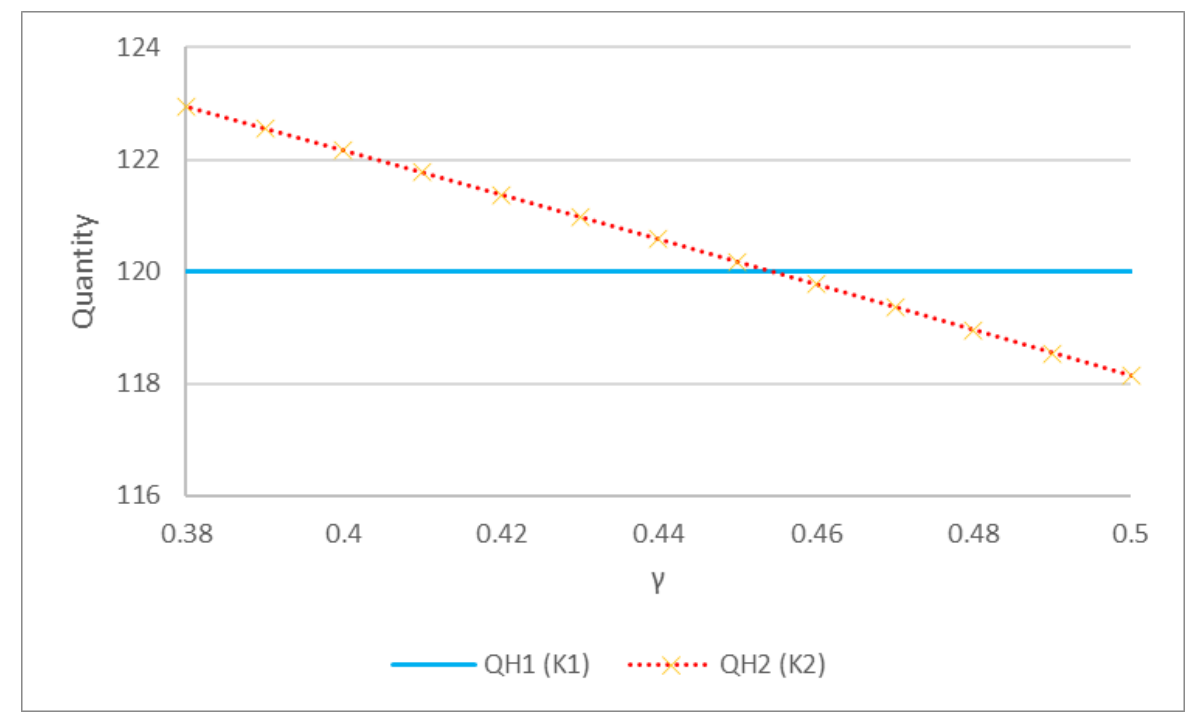

Figure 3. The effect of the change in $\gamma$ on the quantities during the peak period

Figure 4 depicts the effect of the change in the index $\gamma$ on UH. The figure shows that there is no effect on the index in Case 1 , but the index in Case 2 increases with the increase in $\gamma$.

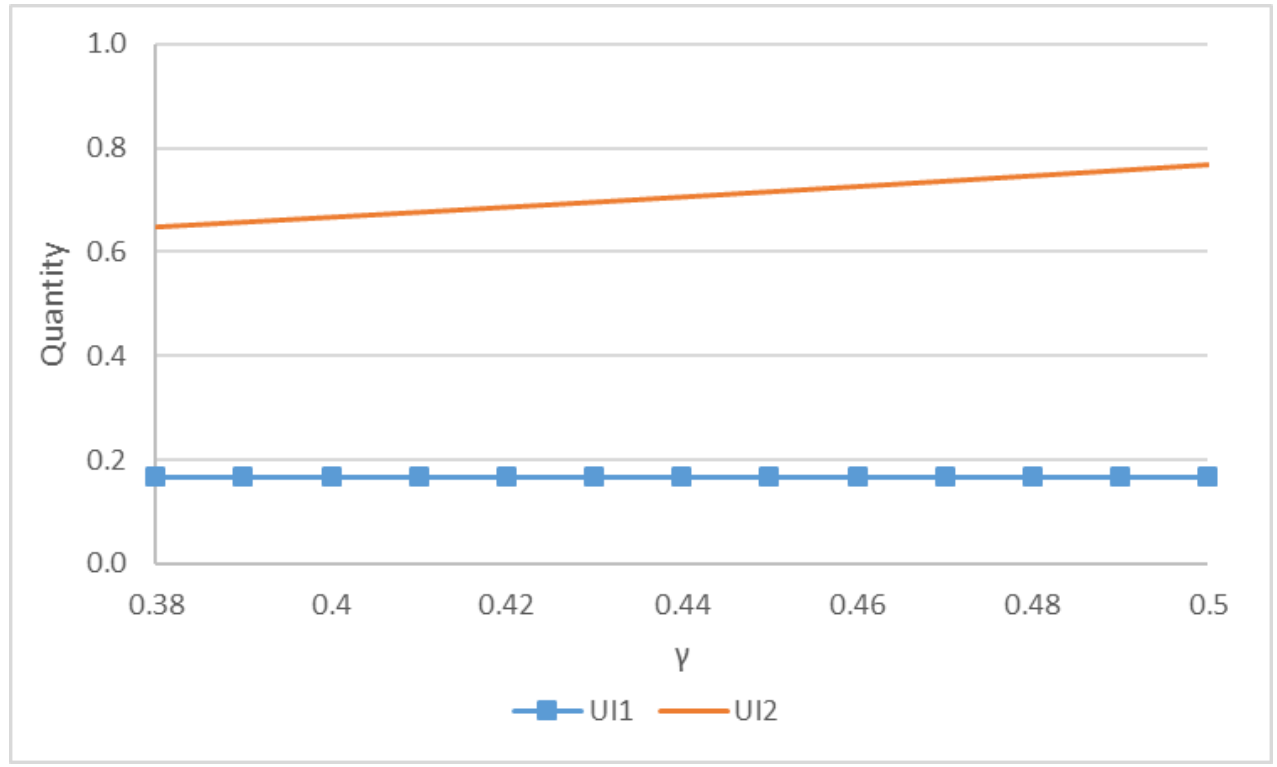

Figure 4. The effect of the change in the index $\gamma$ on UH

1. The optimal price in the peak period as well as the total quantity supplied in both periods are higher in Case 2 than in Case 1. Thus, the profits in Case 2 are greater than in Case 1. The opening of an MP market leads to a very small positive marginal impact.

2. An increase in the value of $H$ has no effect on price and quantity supplied in the regular period, but in both cases leads to a decrease in price in the peak periods. An increase in the value of $\mathrm{H}$ leads to an increase in capacity in both cases.

3. The marginal effect of an increase of $\mathrm{H}$ on the marginal profit is positive and higher in Case 2 than in Case 1 . Therefore, the gap between the profits of the cases increases with $\mathrm{H}$. 
4. The opening of a market for Moving Passengers increases $Q^{M P} . \mathrm{H}$ itself does not have any effect on $Q^{M P}$.

5. $\mathrm{H}$ means that an increase in $\mathrm{H}$ increases the number of vacant seats $Q^{H}$ but not $Q^{M P}$. $E S=K-\left(Q_{2}^{L}+\right.$ $Q^{M P}$ ) is diminishing with the diminishing of $\mathrm{H}$. The levels of $E S$ are particularly low when $\mathrm{H}$ is small. $\mathrm{K}$ is an impediment that is not affected by change in $\mathrm{H}$ and the same applies to $Q^{M P}$ that is not affected by $\mathrm{H}$.

6. When $\gamma$ increases $\gamma=0.5 \Rightarrow Q_{1}^{H}<Q_{2}^{H}$

When $\gamma$ decreases $0.38<\gamma<0.45 \Rightarrow Q_{1}^{H}>Q_{2}^{H}$ but the positive and negative gaps between $Q_{1}^{H}$ and $Q_{2}^{H}$ are very slim.

7. Based on Figure 4, we conclude that the capacity of seats is larger as expected in the case that allows for Moving Passengers that transfer from a peak period to an off-peak period. It is especially larger at higher values of $\gamma$.

8. The capacity, which is the number of planned seats, is on the other hand affected negatively by $\gamma$. This is especially so at a high level of $\mathrm{H}$ that represents for a given level of $\mathrm{L}$ an environment of large fluctuations between periods.

\section{Conclusions}

This paper raises the issue of determining the optimal capacity supplied at every period in the case in which demands fluctuate with peak (high) demand, $\mathrm{H}$, followed by off-peak (regular or low) demand. The profit maximizer who faces in every cycle peak and off-peak demands, may incur costs due to high capacity on one hand; and extra profit in a peak period, combined with too much production in the off-peak period on the other hand.

Two cases are presented. In Case 1 it is not possible to transfer partial demand from a peak period to an off-peak period. In Case 2, it is possible because of the readiness of customers to transfer their demands from a peak to an off-peak period. An example is an airline that faces seasonal high and low demands that should determine the optimal size or number of seats in the aircraft, while also facing costs due to capacity (size) of the aircraft. These costs reflect the cost of the actual use of seats at each period and other costs. (In Case 1 there are no Moving Passengers, while in Case 2 there is some degree of substituity in which some customers are ready to postpone their flight service from a peak to an off-peak period. The questions are how we can compare between the capacities of both cases; what the utilization of these capacities will be; and how the possibility of Moving Passengers affects the phenomenon of empty seats at the off-peak periods and the comparisons regarding pricing, quantities, and profit values of both cases. Some results are trivial and others are not too intuitive, as summarized below.

For a given regular (off-peak) demand we find that if the demand of a peak period is increasingly higher, it will increase peak period prices in both cases. However, in Case 2 it increases by more than in Case 1.

At the same time, the fare for Moving Passengers is also increasing with an increase in the total demand at a peak period. As in the first conclusion above with respect to prices, the same occurs regarding the quantity supplied. An increase in demand at a peak period increases both quantities, i.e. capacities. However, it increases in Case 2 by more than in Case 1 . This is in spite of the fact that part of the increase in the demand at the peak period can be substituted by Moving Passengers.

The results derived from the above conclusions are unequivocal regarding profits. As the demand of the peak period is higher, the profits increase in both cases. However, the possibility of switching demands from peak to off-peak periods increases profits in Case 2 in comparison to Case 1.

The effect of the possibility of switching demand from a peak to an off-peak period enables the reduction of capacity. Still, this negative effect is stronger when the peak demand is larger. The capacity in Case 1 is not affected as expected.

This leads to an important phenomenon. For larger gaps between the demands of peak and off-peak periods, (large $\mathrm{H}$ ), the optimal capacity in Case 1 is larger than the optimal capacity in Case 2. However, with small gaps $(\mathrm{small} \mathrm{H})$ the picture is different. At small $\gamma$, indicating less readiness to switch demand between periods, the capacity in Case 2 is larger than the capacity in Case 1. Yet when $\gamma$ is larger, lower capacity is required in Case 2. Therefore, the capacity in Case 2 is smaller than in Case 1.

The discussion above also leads to a further conclusion regarding the utilizations of the two cases. Due to a greater readiness to switch demands between periods (large $\gamma$ ), less empty seats remain in Case 2 in comparison to Case 1. On the other hand, it is possible that the capacity in Case 2 is smaller than in Case 1 . Thus because of both factors the utilization of seats in Case 2 is significantly higher than in Case 1.

All the conclusions, above, are applied to the case of the airline industry. However, most of these implications can be adapted to different scenarios of daily life, several of which are mentioned below.

One situation concerns the supply of electricity to customers and the optimal turbine capacity for the number of customers 
and quantity of viper hours, when all three elements of capacity, number of users, and total use of electricity require cost. This question that arises in the case of a peak load period and a regular period is very often relevant in the electricity market.

Fluctuations between high season and off season purchases in a department store require determination of the store size (capacity) that affects costs, in addition to those costs due to the number of users and the actual purchases in each period. The extent of purchasing may determine the size of shelves, in addition to the holding cost of the inventory they contain, etc. The same can be applied to regular supermarkets, while their fluctuations in demands occur during the weekend in contrast to weekdays.

The issue of public transportation relates to the size of buses or the number of train cars used in response to different demands during holidays or on regular days.

Congestion issues of driving at rush hours compared to off-peak hours lead to fluctuating demands and require that economic planners consider how many lanes should be paved on each highway. Higher capacity means costs in addition to those that depend upon the number of cars and the distances driven on a highway.

Another similar scenario is found in the area of health economics. The question concerns the optimal size of each hospital department and the number of beds occupied in each season. It is a well-known phenomenon that there are clearly defined fluctuations of hospitalization during the winter and summer seasons. In the winter many patients are hospitalized due to influenza and other seasonal illnesses, in contrast to the summer that is considered a regular off-peak season. The costs structure is again broken down as mentioned above; and the model that is developed can be similarly applied to the other previous examples.

Several examples were presented and many more can be given to emphasize the broad and extensive applicability of the model developed in this paper. In addition, another issue considered in the paper is the possibility of lessening the gaps between peak and regular periods by enabling reduction of the demand at a peak period through shifting part of the demand to a regular period. It is likely almost impossible to do so in the examples of hospitalization or rush hour traffic. However, in the example of flight tickets transferred from peak to regular periods or electricity delivery demands shifted from peak to regular periods, it is definitely possible. The comparison between solutions with and without partial or full substitution of demand is important.

\section{References}

Ashok, S. (2006). Peak-loads management in steel plants. Applied energy, 83, 413-428. https://doi.org/10.1016/j.apenergy.2005.05.002

Ault, R. W., \& Ekelund Jr, R. B. (1987). The Problem of Unnecessary Originality in Economics. Southern Economic Journal, 53(3), 650-61. https://doi.org/10.2307/1058761

Boiteux, M. (1949). La Tarification des demandes en point: appfication de la theorie de la vente aucout marginal. Revue Generale de l'Electicitd, 58, 321-40; translated as 'Peak Load Pricing' (1960). Journal of Business, 33(2), 157-79. https://doi.org/10.1086/294331

Brown, G. Jr., \& Johnson, M. B. (1969). Public Utility Pricing and Output Under Risk. American Economic Review, 59(I), 119-29.

Bye, R. T. (1926). The Nature of Fundamental Elements of Costs. Quarterly Journal of Economics, 41, 30-63. https://doi.org/10.2307/1885552

Bye, R. T. (1929). Composite Demand and Joint Supply in Relation to Public Utility Rates. Quarterly Journal of Economics, 44, 40-62. https://doi.org/10.2307/1885440

Calzada, J. (2003). Capacity charge and peak-load pricing, Working paper, Universi dad de Barcelona.

Carlton, D. W. (1977). Peak-Load Pricing with Stochastic Demands. American Economic Review, 67(5), 1006-10.

Chao, H-P. (1983). Peak-Load Pricing and Capacity Planning with Demand and Supply Uncertainty. Bell Journal of Economics, 14(1), 170-90. https://doi.org/10.2307/3003545

Collard-Wexler, A. (2013). Demand Fluctuations in the Ready-Mix Concrete Industry. Econometrica, 81(3), 1003-1037. https://doi.org/10.3982/ECTA6877

Crampes, C., \& Moreaux, M. (2010). Pumped storage and cost saving. Energy Economics, 32, 325-333. https://doi.org/10.1016/j.eneco.2009.10.004

Crew, M. A., \& Kleindorfer. P. R. (1976). Peak-Load Pricing with a Diverse Technology. Bell Journal of Economics, 7 , 207-31. https://doi.org/10.2307/3003197 
Crew, M. A., \& Kleindorfer, P. R. (1978). Reliability and Public Utility Pricing. American Economic Review, 68(1), 31-40.

Crew, M. A., Fermando, C. S., \& Kleindorfer, P. R. (1995). The Theory of Peak-Load Pricing: A Survey. Journal of Regulatory Economics, 8, 215-248. https://doi.org/10.1007/BF01070807

Cross, R. G. (1997). Revenue Management: Hard-Core Tactics for Market Domination, Broadway Books, New York.

Geraghty, M., \& Johnson, M. (1997). Revenue Management Saves National Car Rental. Interfaces, 12(7), 107-127. https://doi.org/10.1287/inte.27.1.107

Horsley, A., \& Wrobel, A. J. (2002). Efficiency rents of pumped-storage plants and their uses for operation and investment decisions. Journal of Economic Dynamics \& Control, 27, 109-142. https://doi.org/10.1016/S0165-1889(01)00030-6

Houthakker, H. S. (1951). Electricity Tariffs in Theory and Practice. Economic Journal, 61, 1-25. https://doi.org/10.2307/2226608

Ibeas, A., Alonso, B., Dell'Olio, L., \& Moura, J. L. (2014). Bus Size and Headways Optimization Model Considering Elastic Demand. Journal of Transportation Engineering, 140(4), 04013021-1-9. https://doi.org/10.1061/(ASCE)TE.1943-5436.0000641

Jiang, X., Guo, X., \& Ran, B. (2014). Optimization Model for Headway of a Suburban Bus Route. Mathematical Problems in Engineering, Article ID 979062, 6 pages. https://doi.org/10.1155/2014/979062

Joskow, P., \& Tirole, J. (2007). Reliability and competitive electricity markets. Rand Journal of Economics, 38(1), 60-84. https://doi.org/10.1111/j.1756-2171.2007.tb00044.x

Kleindorfer, P. R., \& Fermando, C. S. (1993). Peak-Load Pricing and Refiability under Uncertainty. Journal of Regulatory Economics, 5(1), 5-23. https://doi.org/10.1007/BF01066311

Kopsch, F. (2012). A demand model for domestic air travel in Sweden. Journal of Air Transport Management, 20, 46-48. https://doi.org/10.1016/j.jairtraman.2011.11.006

Laffont, J-J., \& Tirole, J. (2000). Competition in Telecommunications (Cam bridge, MA: MIT Press).

Lamont, A. D. (2013): Assessing the economic value and optimal structure of large-scale electricity storage. In: IEEE Trans. Power Syst, 28(2), 911-921. https://doi.org/10.1109/TPWRS.2012.2218135

Lazear, E. P. (2001). Educational Production. The Quarterly Journal of Economics, 116(3), 777-803. https://doi.org/10.1162/00335530152466232

Lewis, W. A. (1941). The Two-Part Tariff. Economiea, 8, 249-70. https://doi.org/10.2307/2549332

Lieberman, W. (1992). Implementing Yield Management. ORSA/TIMS National Meeting Presentation, November, San Francisco, California.e, I.

Munasinghe, M., \& Sanghvi, A. (1988). Reliability of Electricity Supply, Outage Costs and Value of Service: An Overview. The Energy Journal, 9 (Special Issue on Electricity Reliability), 1-18. https://doi.org/10.5547/ISSN0195-6574-EJ-Vol9-NoSI2-1

Peng, B., Song, H., Crouch, G. I., \& Witt, S. F. (2015). A Meta-Analysis of International Tourism Demand Elasticities. Journal of Travel Research, 54(5), 611- 633. https://doi.org/10.1177/0047287514528283

Sherman, R., \& Visscher, M. (1978). Second Best Pricing with Stochastic Demand. American Economic Review, 68(1), 41-53.

Shy, O. (2001). Dynamic peak-load pricing, working paper, University of Haifa and Stockholm school of economics.

Smith, B. C., Leimkuhler, J. F., \& Darrow, R. M. (1992). Yield Management at American Airlines, Interfaces, 22(1), 8-31. https://doi.org/10.1287/inte.22.1.8

Steffen, B., \& Weber, C. (2013): Efficient storage capacity in power systems with thermal and renewable generation. In: Energy Economics, 36, 556-567. https://doi.org/10.1016/j.eneco.2012.11.007

Steiner, P. O. (1957). Peak Loads and Efficient Pricing. Quarterly Journal of Economics, 71, 585-610. https://doi.org/10.2307/1885712

Telson, M. (1975). The Economics of Alternative Levels of Reliability for Electric Power Generation Systems, Bell Journal of Economics, 6(2), 679-94. https://doi.org/10.2307/3003250

Visscher, M. L. (1973). Welfare-Maximizing Price and Output with Stochastic Demand: Comment. American Economic 
Review, 63(1), 224-29.

Yang, X., Zhang, Y., \& Ji, H. (2015). Bus service frequency and bus size optimization model considering passengers' perception.

Zervas, G., \& Proserpio, D., \& Byers, J. W. (2017). The Rise of the Sharing Economy: Estimating the Impact of Airbnb on the Hotel Industry. Journal of Marketing Research, LIV, 687-705. https://doi.org/10.1509/jmr.15.0204

\section{Copyrights}

Copyright for this article is retained by the author(s), with first publication rights granted to the journal.

This is an open-access article distributed under the terms and conditions of the Creative Commons Attribution license (http://creativecommons.org/licenses/by/4.0/). 